\title{
Highly dispersed gold on activated carbon fibers for low-temperature $\mathrm{CO}$ oxidation
}

\author{
Dmitri A. Bulushev, ${ }^{\mathrm{a}}$ Igor Yuranov, ${ }^{\mathrm{a}}$ Elena I. Suvorova, ${ }^{\mathrm{b}}$ Philippe A. Buffat, ${ }^{\mathrm{b}}$ and \\ Lioubov Kiwi-Minsker ${ }^{\mathrm{a}, *}$ \\ a Swiss Federal Institute of Technology, LGRC-EPFL, CH-1015 Lausanne, Switzerland \\ $\mathrm{b}$ Swiss Federal Institute of Technology, CIME-EPFL, CH-1015 Lausanne, Switzerland
}

Received 12 August 2003; revised 5 February 2004; accepted 7 February 2004

\begin{abstract}
Gold nanoparticles of 2-5 nm supported on woven fabrics of activated carbon fibers (ACF) were effective during $\mathrm{CO}$ oxidation at room temperature. To obtain a high metal dispersion, $\mathrm{Au}$ was deposited on $\mathrm{ACF}$ from aqueous solution of ethylenediamine complex $\left[\mathrm{Au}(\mathrm{en})_{2}\right] \mathrm{Cl}_{3}$ via ion exchange with protons of surface functional groups. The temperature-programmed decomposition method showed the presence of two main types of functional groups on the ACF surface: the first type was associated with carboxylic groups easily decomposing to $\mathrm{CO}_{2}$ and the second one corresponded to more stable phenolic groups decomposing to $\mathrm{CO}$. The concentration and the nature of surface functional groups was controlled using $\mathrm{HNO}_{3}$ pretreatment followed by either calcination in $\mathrm{He}(300-1273 \mathrm{~K})$ or by iron oxide deposition. The phenolic groups are able to attach $\mathrm{Au}^{3+}$ ions, leading to the formation of small Au nanoparticles $(<5 \mathrm{~nm})$ after reduction by $\mathrm{H}_{2}$. This was confirmed by high-resolution electron microscopy combined with X-ray energy-dispersive analysis. The catalyst with high Au dispersion demonstrated high activity in $\mathrm{CO}$ oxidation. The surface carboxylic groups decomposed during interaction with $\left[\mathrm{Au}\left(\mathrm{en}_{2}\right)_{2} \mathrm{Cl}_{3}\right.$ solution and reduced $\mathrm{Au}^{3+}$ to $\mathrm{Au}^{0}$, resulting in the formation of bigger $(>9 \mathrm{~nm}) \mathrm{Au}$ agglomerates after reduction by $\mathrm{H}_{2}$. These catalysts demonstrated lower activity as compared to the ones containing mostly small Au nanoparticles. Complete removal of surface functional groups rendered an inert support that would not interact with the Au precursor. The oxidation state of gold in the Au/ACF catalysts was controlled by X-ray photoelectron spectroscopy before and after the reduction in $\mathrm{H}_{2}$. The high-temperature reduction in $\mathrm{H}_{2}(673-773 \mathrm{~K})$ was necessary to activate the catalyst, indicating that metallic gold nanoparticles are active during catalytic $\mathrm{CO}$ oxidation.
\end{abstract}

(c) 2004 Elsevier Inc. All rights reserved.

Keywords: CO oxidation; Nanoparticles of gold; Activated carbon fibers; Structured supports; Surface functional groups; Iron oxide; HRTEM; XPS; TPD

\section{Introduction}

The unique properties of supported gold to catalyze different reactions at low temperatures has been an active field of research during the past decade [1-5]. The high activity of these catalysts is assigned to Au nanoparticles with the size of 2-6 nm. The gold nanoparticles on oxides like $\mathrm{Al}_{2} \mathrm{O}_{3}$, $\mathrm{SiO}_{2}, \mathrm{TiO}_{2}, \mathrm{MgO}$, and $\mathrm{Fe}_{2} \mathrm{O}_{3}$ have been thoroughly studied, giving evidence of their activity dependence on the $\mathrm{Au}$ particle size and on the nature of the support [1-5]. Thus, for oxidation of $\mathrm{CO}$ to $\mathrm{CO}_{2}$, it was found that the $\mathrm{Au} / \mathrm{TiO}_{2}$ catalysts are about 1 order of magnitude more active than $\mathrm{Au} / \mathrm{SiO}_{2}$ catalysts [6].

\footnotetext{
* Corresponding author. Fax: +41 216933190.

E-mail address: lioubov.kiwi-minsker@epfl.ch (L. Kiwi-Minsker).
}

Activated carbon (AC) supports have been seldom used for gold deposition in spite of the advantages of the AC compared to oxide supports such as (1) a high specific surface area up to $3000 \mathrm{~m}^{2} / \mathrm{g}$, (2) high stability in acidic and basic media [7], and (3) easy recovery of supported metals by burning off the catalyst. Prati et al. [8,9] showed that the $\mathrm{Au} / \mathrm{AC}$ catalysts are active in different liquid-phase reactions, but the activities of these catalysts are sensitive to the preparation method.

In our previous work [10] we presented the first evidence for structured catalysts consisting of Au supported on activated carbon fibers (ACF) efficient during $\mathrm{CO}$ oxidation at low temperatures. The activity was comparable to the most active Au/oxide catalysts. These catalysts gain advantage from the sorption properties of ACF, the suitable structure of the fabrics, and the high activity of gold nanoparticles. The latter combination leads to novel catalytic materials useful 
in environmental protection. This study is warranted since catalysts effective for $\mathrm{CO}$ oxidation at ambient temperatures have wide applications for air purification, especially in breathing apparatuses.

ACF have been used as supports for platinum [11] and palladium [12] as well as adsorbents in wastewater treatment to separate heavy metals and recover precious metals from diluted solutions $[7,13,14]$.

Deposition of noble metals with high dispersion on $\mathrm{AC}$ is not a trivial task due to the tendency of metals toward agglomeration. The interaction of precursor cations and anions with carbon is accompanied by metal reduction [11, 15-17]. Thus, the Au particles size distribution on AC deposited from $\mathrm{HAuCl}_{4}$ has been found to be bimodal, containing a significant fraction of large particles $[9,18]$. This effect could be explained by the wide range of oxygen-containing functional groups present on the AC surface [19-23]. These groups have properties that determine the support interaction with the Au precursor. The concentration and the nature of different functional groups are known to depend on the $\mathrm{AC}$ pretreatment by acids and bases and can be regulated by thermal treatment in different atmospheres. The influence of AC surface functional groups on the dispersion of transition metals on the catalyst surface was discussed earlier for $\mathrm{Pt}$ and Pd [11,24-26], as well as for the Au/AC catalysts [27], but the cation exchange with protons of surface groups has not been investigated during the preparation of highly dispersed gold on activated carbon.

The objective of this work is to understand the role of the ACF surface functional groups and the effect of Au precursor on the size of Au nanoparticles aiming to improve catalyst activity during low-temperature $\mathrm{CO}$ oxidation. To tailor the Au-nanocrystalite sizes, ACF pretreatment was designed to control the chemical uniformity of the surface groups involved in ion exchange with Au precursor. Ion exchange using ethylenediamine complex $\left[\mathrm{Au}(\mathrm{en})_{2}\right] \mathrm{Cl}_{3}$ was chosen as a preparation method to improve the Au dispersion. It was compared with conventional Au deposition from $\mathrm{HAuCl}_{4}$ aqueous solution.

The surface functional group's concentration on ACF was characterized by temperature-programmed decomposition (TPD). Information pertaining to the size and oxidation state of Au particles on ACF before and after reduction in hydrogen was obtained from high-resolution transmission microscopy (HRTEM) combined with X-ray energydispersive analysis (EDAS) and X-ray photoelectron spectroscopy (XPS).

\section{Experimental}

\subsection{Catalyst preparation}

\subsubsection{Materials}

The following materials, gold(III) chloride hydrate $\mathrm{HAuCl}_{4} \cdot \mathrm{aq}$, iron(III) nitrate $\mathrm{Fe}\left(\mathrm{NO}_{3}\right)_{3} \cdot 9 \mathrm{H}_{2} \mathrm{O}$, ethylenediamine $\mathrm{NH}_{2} \mathrm{C}_{2} \mathrm{H}_{4} \mathrm{NH}_{2}$ (en), and aqueous ammonia (28 wt\%), were of "p.a." quality and purchased from Fluka (Buchs, Switzerland). [Au(en $\left.)_{2}\right] \mathrm{Cl}_{3}$ was synthesized from $\mathrm{HAuCl}_{4}$. aq and ethylenediamine as described elsewhere [28].

Granulated activated carbon (Darko, Aldrich) was used as a support without any pretreatment. Activated carbon fibers (ACF) in the form of a woven fabric (AW1101, KoTHmex, Taiwan Carbon Technology Co.) were used as supports as received and after different pretreatments.

\subsubsection{Modification of the support by $\mathrm{HNO}_{3}$ and thermal treatment}

The ACF were used both without any pretreatment (denoted as ACF-original) and after different pretreatments by varying the composition of the surface functional groups. The materials used and the pretreatment conditions are listed in Table 1. The fibers were boiled in aqueous $\mathrm{HNO}_{3}$ $(15 \mathrm{vol} \%)$ for $1 \mathrm{~h}$, rinsed with water, air-dried at room temperature (denoted as $\mathrm{ACF}\left(\mathrm{HNO}_{3}\right)$ ), and underwent the calcinations in $\mathrm{He}(100 \mathrm{ml} / \mathrm{min})$ for $30 \mathrm{~min}$ in a quartz reactor at temperatures of 573, 773, 973, and $1273 \mathrm{~K}$ (temperature ramp, $10 \mathrm{~K} / \mathrm{min}$ ).

\subsubsection{Modification of the support by iron oxide}

For the preparation of ACF modified by iron oxide $\left(\mathrm{FeO}_{x} / \mathrm{ACF}\right)$ the ACF fabric pretreated in $\mathrm{HNO}_{3}$ was immersed into aqueous solution of $\mathrm{Fe}\left(\mathrm{NO}_{3}\right)_{3} \cdot 9 \mathrm{H}_{2} \mathrm{O}(10 \mathrm{wt} \%)$, which was hydrolyzed: (i) by slow addition of ammonia $(1 \mathrm{~h})$ until $\mathrm{pH} 3$ under vigorous stirring or (ii) by slow increasing

Table 1

Characteristics of the catalysts and support pretreatments

\begin{tabular}{lllll}
\hline Catalyst & $\mathrm{Au}$ content $(\mathrm{wt} \%)$ & $\mathrm{HNO}_{3}$ pretreatment & Pretreatment in He & $\mathrm{SSA}_{\mathrm{BET}}\left(\mathrm{m}^{2} \mathrm{~g}^{-1}\right)$ \\
\hline $1.1 \% \mathrm{Au} / \mathrm{ACF}$ (original) & 1.1 & No & No & 880 \\
$0.8 \% \mathrm{Au} / \mathrm{ACF}\left(\mathrm{HNO}_{3}\right)$ & 0.8 & Yes & No & 950 \\
$1.2 \% \mathrm{Au} / \mathrm{ACF}\left(\mathrm{HNO}_{3}, 573 \mathrm{~K}\right)$ & 1.2 & Yes & $573 \mathrm{~K}$ & - \\
$1.0 \% \mathrm{Au} / \mathrm{ACF}\left(\mathrm{HNO}_{3}, 773 \mathrm{~K}\right)$ & 1.0 & Yes & $773 \mathrm{~K}$ & - \\
$0.7 \% \mathrm{Au} / \mathrm{ACF}\left(\mathrm{HNO}_{3}, 973 \mathrm{~K}\right)$ & 0.7 & Yes & $973 \mathrm{~K}$ & - \\
$0.04 \% \mathrm{Au} / \mathrm{ACF}\left(\mathrm{HNO}_{3}, 1273 \mathrm{~K}\right)$ & 0.04 & Yes & No & 650 \\
$4.8 \% \mathrm{Au} / \mathrm{ACF}$ (original) & 4.8 & No & No & 880 \\
$1.5 \% \mathrm{Au} / \mathrm{C}$ (granulated) & 1.5 & No & & 660 \\
\hline
\end{tabular}


$\mathrm{pH}$ up to 3.5 using urea as a precipitating agent under stirring at $353 \mathrm{~K}$. Finally, the ACF fabrics were boiled in water for $1 \mathrm{~h}$ and dried in air at room temperature.

\subsubsection{Preparation of gold catalysts}

An aqueous solution of ethylenediamine complex $\left[\mathrm{Au}(\mathrm{en})_{2}\right] \mathrm{Cl}_{3}$ was mostly used as a gold precursor. The ACF or $\mathrm{FeO}_{x} / \mathrm{ACF}$ fabrics $(2 \mathrm{~g})$ were immersed in a stirred $\left[\mathrm{Au}(\mathrm{en})_{2}\right] \mathrm{Cl}_{3}$ aqueous solution $(20 \mathrm{ml})$ for $3 \mathrm{~h}$. The $\left[\mathrm{Au}(\mathrm{en})_{2}\right] \mathrm{Cl}_{3}$ initial concentration in the solution was varied from 0.05 to $0.2 \mathrm{wt} \%$ to obtain different concentrations of gold in the catalyst. After $\left[\mathrm{Au}(\mathrm{en})_{2}\right] \mathrm{Cl}_{3}$ adsorption, the fabrics were rinsed with water and dried in air at room temperature. Sometimes the $\mathrm{HAuCl}_{4}$ solution was also employed for comparison.

\subsection{Catalyst characterization}

The concentrations of $\mathrm{Fe}$ and $\mathrm{Au}$ were measured by atomic absorption spectroscopy (AAS) using a Shimadzu AA-6650 spectrophotometer with an air-acetylene flame. For the analysis the ACF-based catalysts were heated in air at $973 \mathrm{~K}$ for $2 \mathrm{~h}$ to burn off the carbon support, and the mineral residue was dissolved in hot aqua regia containing a few drops of HF.

Characterization of the functional groups on the support surface after different pretreatments was performed by temperature-programmed decomposition (TPD) method in $\mathrm{He}(100 \mathrm{ml} / \mathrm{min}$, ramp rate $10 \mathrm{~K} / \mathrm{min})$ using a Micromeritics AutoChem 2910 analyzer. In these experiments $0.010 \mathrm{~g}$ of ACF was placed in a quartz plug-flow reactor. The TPD products were analyzed by a ThermoStar-200 quadrupole mass spectrometer (Pfeiffer Vacuum) calibrated using the gas mixtures of known compositions. The intensity of the following peaks was measured simultaneously: $2,4,15,18$, $28,30,32$, and $44 \mathrm{~m} / e$. The reaction temperature was controlled by a thermocouple inserted inside the catalyst bed. Before the TPD runs the charged reactor was purged in $\mathrm{He}$ for $30 \mathrm{~min}$ at room temperature.

The elemental surface composition of the catalysts was controlled by XPS using an Axis Ultra ESCA system (Kratos, Manchester) with monochromated $\mathrm{Al}-\mathrm{K}_{\alpha}$ radiation $(1486.6 \mathrm{eV})$ and an X-ray power of $150 \mathrm{~W}$. The binding energy (BE) scale was referenced against C $1 s=285.0 \mathrm{eV}$ line.

The surface morphology of the catalysts was investigated by high-resolution transmission electron microscopy (Philips CM300UT FEG with 300-kV field emission gun, $0.65-\mathrm{mm}$ spherical aberration, and $0.17-\mathrm{nm}$ resolution at Scherzer defocus). A chemical analysis was performed with X-ray energy-dispersive analysis (EDS, INCA, Oxford) with probes of 2-8 $\mathrm{nm}$ in diameter.

To study the distribution of gold and iron over an elementary carbon filament, the samples for HRTEM were prepared by ultramicrotomy. For this purpose an ACF thread was embedded in epoxy resin and cut with a $45^{\circ}$ diamond knife at room temperature to obtain the slices of filament cross section. Slices of 20-50 nm thickness were picked up from water by means of a metallic loop and transferred onto the holey carbon film for examination.

The HRTEM images were recorded on a Gatan 797 slowscan CCD camera $(1024 \times 1024$ pixels $)$ and processed with the Gatan Digital Micrograph 3.6.1 software to measure distances and angles between atomic planes. A description of quantitative analysis by EDS and phase identification could be found elsewhere [10].

The specific surface area (SSA) of the supports was measured using $\mathrm{N}_{2}$ adsorption-desorption at $77 \mathrm{~K}$ in a Sorptomatic 1990 instrument (Carlo Erba). The samples were heated in vacuum at $523 \mathrm{~K}$ for $2 \mathrm{~h}$ before the measurements. The SSA of the samples was calculated employing the BET method.

\subsection{Catalytic activity measurements}

A Micromeritics AutoChem 2910 analyzer was used for catalytic activity measurements. It allowed quick changing of one gas flow over the catalyst to another. Before the study all samples were preheated in the reactor in pure $\mathrm{H}_{2}$ until 573,673 , or $773 \mathrm{~K}(5 \mathrm{~K} / \mathrm{min})$, maintained at this temperature for $30 \mathrm{~min}$, and then quickly cooled down in $\mathrm{H}_{2}$ to room temperature by opening the furnace. This pretreatment was necessary to activate the catalyst. After the reduction, the catalysts were purged by $\mathrm{He}$ for $15 \mathrm{~min}$ at room temperature before introducing the reaction mixture. The 1 vol\% CO, $5 \mathrm{vol} \% \mathrm{O}_{2}, 45 \mathrm{vol} \% \mathrm{He}$, and 49 vol\% Ar mixture with the total gas flow of 20 or $100 \mathrm{ml}$ (STP)/min was used throughout the study. The gases were of $>99.999 \%$ purity (CarbaGas, Switzerland).

The products in the reactor outlet were analyzed by mass spectrometer. The $\mathrm{CO}$ conversion was determined as the concentration of $\mathrm{CO}_{2}$ related to the initial $\mathrm{CO}$ concentration in the reaction mixture. The carbon balance was controlled during the experiments. It was within $100 \pm 2 \%$. The reaction rate was determined under differential conditions at conversions $<0.15$.

\section{Results and discussion}

\subsection{Optimization of the catalyst preparation with respect to the activity in $\mathrm{CO}$ oxidation}

The type of precursor suitable for the Au deposition first was considered. The utilization of $\mathrm{HAuCl}_{4}$ aqueous solution was observed to result in fast metallization of the external surface of the supports (ACF fabrics became glittery), independent of the support pretreatment. These observations are in line with the results reported earlier [16] as well as with the formation of big and small Au particles found after $\mathrm{HAuCl}_{4}$ interaction with $\mathrm{AC}$ followed by the reduction of the catalyst in formic acid [18]. The results of the catalytic 


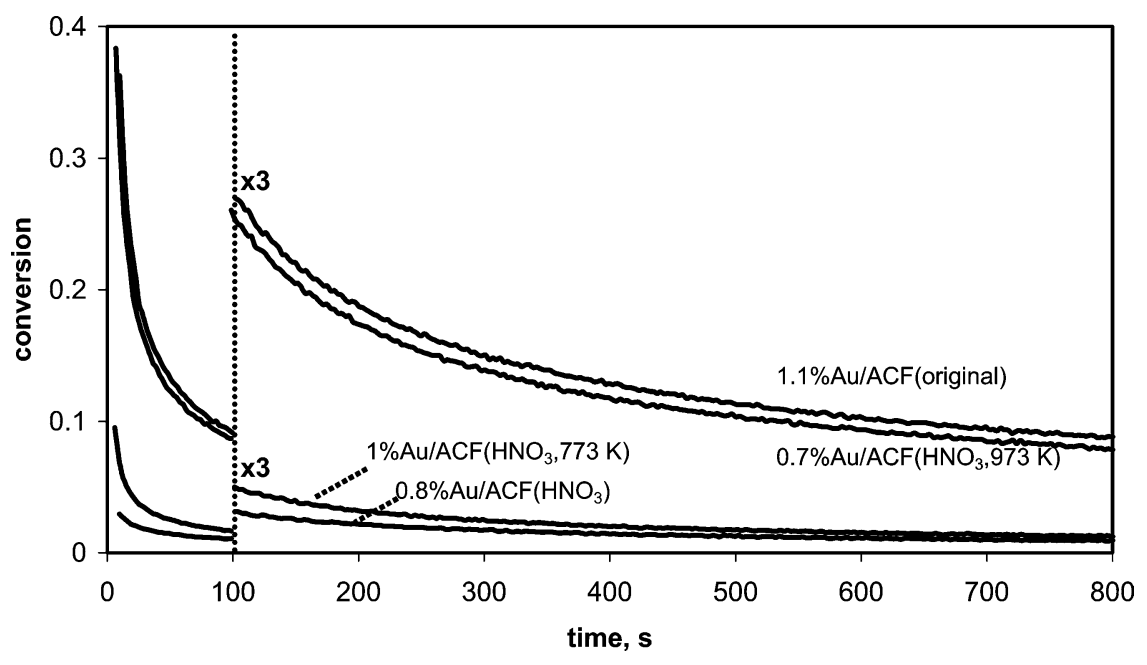

Fig. 1. The conversion-time dependence during $\mathrm{CO}$ oxidation at room temperature $\left(1 \mathrm{vol} \% \mathrm{CO}, \mathrm{O}_{2} / \mathrm{CO}=5,100 \mathrm{ml} / \mathrm{min}\right)$ over different Au/ACF catalysts $(0.02 \mathrm{~g})$, activated in $\mathrm{H}_{2}$ at $673 \mathrm{~K}$.

tests of our samples prepared from $\mathrm{HAuCl}_{4}$ showed that the activity in $\mathrm{CO}$ oxidation was very low, being in agreement with the presence of big Au particles, which show negligible activity during the catalytic reaction. This agrees with the catalytic testing of the $\mathrm{Au} / \mathrm{AC}$ catalysts prepared from $\mathrm{HAuCl}_{4}$ in liquid-phase alcohol oxidation [9].

The deposition of gold from $\left[\mathrm{Au}(\mathrm{en})_{2}\right] \mathrm{Cl}_{3}$ on ACF was found to be dependent on the concentration of ethylenediamine. In the excess of ethylenediamine ( $\mathrm{pH} 9-10)$ no deposition of gold was observed, while from 60 to $80 \%$ of $\left[\mathrm{Au}(\mathrm{en})_{2}\right] \mathrm{Cl}_{3}$ was deposited on the ACF in neutral media (pH 5-6). This fact allows the suggestion of a competition of ethylenediamine and $\left[\mathrm{Au}(\mathrm{en})_{2}\right]^{3+}$ cations for acidic functional groups of ACF, indicating that cation exchange is the main mechanism of Au deposition.

The effect of the support pretreatment on the obtained catalysts was examined in detail. As seen in Table 1, the boiling in $\mathrm{HNO}_{3}$ changes the SSA of ACF only slightly. The performed thermal treatment in He decreased the SSA of the support less than 1.5 times. After the support calcinations in $\mathrm{He}$ at $1273 \mathrm{~K}$, the amount of gold, which could be deposited on $\mathrm{ACF}$ from $\left[\mathrm{Au}(\mathrm{en})_{2}\right] \mathrm{Cl}_{3}$, decreased from $\sim 1$ to $0.04 \mathrm{wt} \%$, pointing out the loss of functional groups from the ACF surface, which were active during the ion exchange.

Fig. 1 shows the time dependence of $\mathrm{CO}$ conversion over the $\mathrm{Au} / \mathrm{ACF}$ samples with approximately the same amount of gold (0.7-1.1 wt\%, Table 1) after reduction in $\mathrm{H}_{2}$ at $673 \mathrm{~K}$. For all the catalysts a strong initial deactivation is observed (Fig. 1). We found similar behavior for the $\mathrm{Au} / \mathrm{FeO}_{x} / \mathrm{ACF}$ catalysts [10]. The initial activity and dynamics of deactivation were reproducible after the reductive reactivation in $\mathrm{H}_{2}$; hence, the deactivation cannot be related to a change of the Au particle size during the reaction carried out at room temperature. This result is in line with the data reported by Grisel and Nieuwenhuys [29] who observed only a small change of the Au particle size after $\mathrm{CO}$ oxidation over $\mathrm{Au} / \mathrm{Al}_{2} \mathrm{O}_{3}$ at temperatures up to $573 \mathrm{~K}$. Additionally, the presence of hydrogen and water vapor in the reactive mixture was found to increase the activity of the $\mathrm{Au} / \mathrm{ACF}$ catalysts in agreement with the results for the $\mathrm{Au} / \mathrm{FeO}_{x} / \mathrm{ACF}$ catalysts [10]. Thus, deactivation was ascribed to the partial oxidation of Au particles in the reaction mixture [10].

The catalyst prepared by $\mathrm{Au}$ deposition on the $\operatorname{ACF}\left(\mathrm{HNO}_{3}\right)$ without any thermal treatment possesses the lowest steady-state activity in $\mathrm{CO}$ oxidation. The thermal pretreatment of ACF in $\mathrm{He}$ at temperatures $\leqslant 773 \mathrm{~K}$ leads to a more active Au catalyst. A strong increase was observed for the Au catalyst on the ACF support pretreated in $\mathrm{He}$ at $973 \mathrm{~K}$. The conversion in that case was close to the one of the Au catalyst based on the original ACF without any pretreatment.

Thus, the activity of the Au/ACF catalyst depends on the pretreatment of the ACF support before Au deposition. It allows the suggestion that the pretreatment influences the surface functional groups affecting the catalytic properties of Au particles obtained.

The initial activity of the catalysts (during the first 10 min) after reduction in $\mathrm{H}_{2}$ at different temperatures was studied and is shown in Fig. 2. The reduction of gold does not take place at $473 \mathrm{~K}$ and lower temperatures (not shown) and the activity of such catalysts was negligible. The increase of the reduction temperature to 573-773 K results in an increased activity of Au/ACF. This was observed for all Au/ACF catalysts independent of the pretreatment of the support. The difference in activity between 673 and $773 \mathrm{~K}$ is small, indicating a complete reduction of gold by $\mathrm{H}_{2}$ under these conditions, leading to the active Au nanoparticles. At higher reduction temperatures a stronger sintering leads to agglomeration of Au clusters and to a decrease of the activity. The results obtained allow the conclusion that the metallic gold in nanoparticles is active during $\mathrm{CO}$ oxidation.

The catalytic performance of the catalysts with different metal loadings: $1.1 \% \mathrm{Au} / \mathrm{ACF}$ (original) and $4.8 \%$ $\mathrm{Au} / \mathrm{ACF}$ (original) reduced at the same temperature $(673 \mathrm{~K})$ 


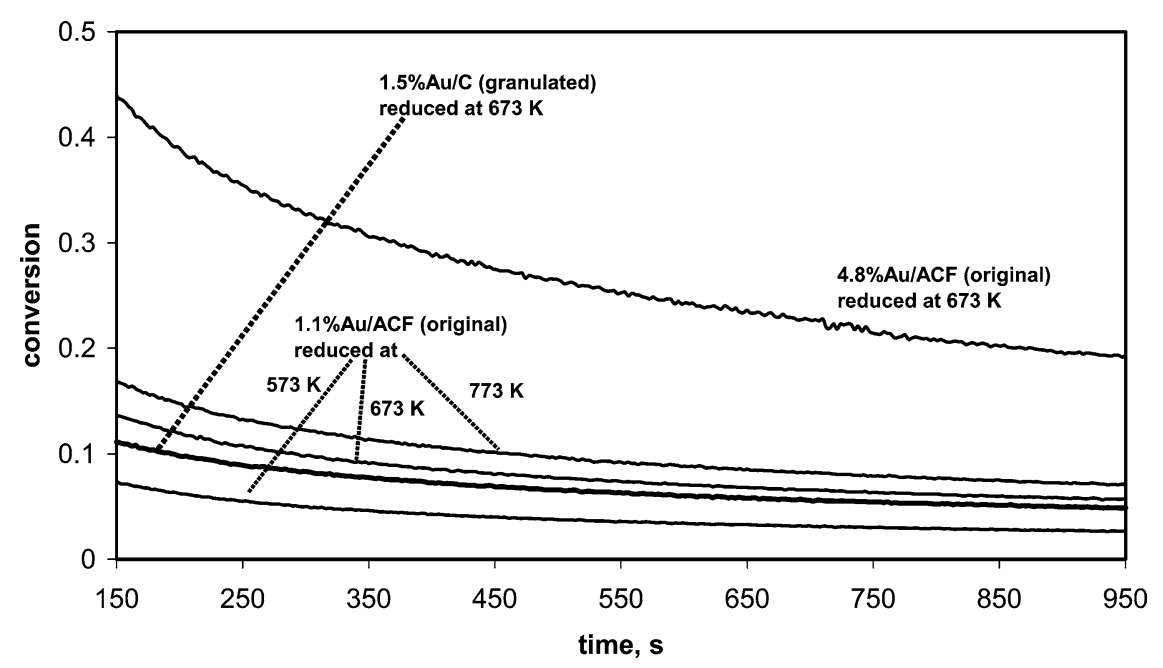

Fig. 2. The conversion-time dependence during $\mathrm{CO}$ oxidation at room temperature ( 1 vol $\left.\% \mathrm{CO}, \mathrm{O}_{2} / \mathrm{CO}=5,100 \mathrm{ml} / \mathrm{min}\right)$ over the $\mathrm{Au} / \mathrm{ACF}$ and $\mathrm{Au} / \mathrm{C}$ catalysts $(0.02 \mathrm{~g})$ activated in $\mathrm{H}_{2}$ at different temperatures.

is shown in Fig. 2. The catalyst activity was proportional to the amount of $\mathrm{Au}$. This suggests that in the investigated concentration range of gold roughly the same average $\mathrm{Au}$ particle size was attained.

The CO conversion over the $1.5 \% \mathrm{Au} / \mathrm{C}$-granulated was found to be close to the conversion over the $1.1 \%$ Au/ACF(original) (Fig. 2). A similar deactivation was also observed, suggesting the same general features for Au supported on granulated AC.

To understand the relationship between catalytic activities and the size of Au nanoparticles along with their oxidation state, the supports and the catalysts were characterized by TPD, XPS, and HRTEM combined with EDAS.

\subsection{Characterization of the ACF supports}

Fig. 3 shows the TPD profiles obtained from the thermally treated $\mathrm{ACF}\left(\mathrm{HNO}_{3}\right)$. It is seen that the release of $\mathrm{CO}_{2}$ starts at lower temperatures than $\mathrm{CO}$. The profile of $\mathrm{CO}_{2}$ is very broad, indicating decomposition of several types of surface groups. The first $\mathrm{CO}_{2}$ peak is accompanied by a $\mathrm{H}_{2} \mathrm{O}$ peak (not shown). Literature TPD data combined with DRIFTS, XPS, and titration methods data [13,20-23,30] reported that the low-temperature $\mathrm{CO}_{2}$ evolution $(\sim 540 \mathrm{~K})$ is due to carboxylic groups decomposition. The decomposition of the derivatives of these groups like lactol and lactone groups was observed at higher temperatures (650-940 K). Carboxylic anhydride groups decomposed with simultaneous $\mathrm{CO}$ and $\mathrm{CO}_{2}$ formation at $700-840 \mathrm{~K}$. Phenolic groups $(\sim 900 \mathrm{~K})$ and carbonyl/quinone groups $(\sim 1080 \mathrm{~K})$ are the most stable on the AC surface and decompose with $\mathrm{CO}$ evolution. Hydrogen formation was also observed at temperatures higher than $960 \mathrm{~K}$.

The dependence of the $\mathrm{CO}$ and $\mathrm{CO}_{2}$ amounts evolved during TPD on the pretreatment temperature is shown in Fig. 4. The surface hydroxyls associated with the carboxylic groups giving $\mathrm{CO}_{2}$ during thermal treatment were removed at temperatures from 350 to $973 \mathrm{~K}$. In contrast, the surface hydroxyls associated with the phenolic groups evolving $\mathrm{CO}$ decompose at temperatures above $773 \mathrm{~K}$. A pretreatment at $1273 \mathrm{~K}$ removes all precursors of $\mathrm{CO}$ and $\mathrm{CO}_{2}$ (Figs. 3 and 4). So $\left[\mathrm{Au}(\mathrm{en})_{2}\right] \mathrm{Cl}_{3}$ solution does not interact with such support, indicating that surface acidic functional groups are responsible for this interaction. Deposition of gold from $\mathrm{HAuCl}_{4}$ solution on the support pretreated in $\mathrm{He}$ at $1273 \mathrm{~K}$ results in a quick reduction of gold by carbon (metallization of the ACF external surface was observed).

The catalyst $0.7 \% \mathrm{Au} / \mathrm{ACF}\left(\mathrm{HNO}_{3}, 973 \mathrm{~K}\right)$ based on the ACF support not containing carboxylic groups (Fig. 4) demonstrated the highest activity (Fig. 1). Thus, we conclude that phenolic groups, which remain stable during calcinations in $\mathrm{He}$, are responsible for the observed ion exchange with $\left[\mathrm{Au}(\mathrm{en})_{2}\right]^{3+}$ leading to the Au nanoparticles after the catalyst reduction in $\mathrm{H}_{2}$.

The $\mathrm{CO}_{2}$ TPD profiles of the original and $\mathrm{HNO}_{3}$ treated ACF are compared in Fig. 5 (curves 1 and 4). The ACF(original) evolves much less $\mathrm{CO}_{2}$ as compared to $\mathrm{ACF}\left(\mathrm{HNO}_{3}\right)$ (about 4 times). At the same time the difference in the surface group's concentration of the $\mathrm{CO}$ precursors is only 1.5 times. A low concentration of carboxylic groups on the $\mathrm{ACF}$ (original) surface with respect to the $\mathrm{ACF}\left(\mathrm{HNO}_{3}\right)$ one makes it a suitable support for the formation of active Au nanoparticles (Fig. 1).

\subsection{Au/ACF catalysts formation}

The $\mathrm{CO}_{2}$ and $\mathrm{CO}$ TPD profiles of the $\mathrm{ACF}$ (original) before and after deposition of $4.8 \mathrm{wt} \%$ Au are shown in Fig. 6. The amounts of evolved $\mathrm{CO}_{2}$ and $\mathrm{CO}$ are decreased after $\mathrm{Au}$ deposition, indicating that both carboxylic and phenolic groups were involved in this process. The amount of $\mathrm{CO}_{2}$ evolved from the initial support $\mathrm{ACF}$ (original) was $0.61 \mathrm{mmolg}^{-1}$, and after deposition of $4.8 \mathrm{wt} \% \mathrm{Au}$ decreased to $0.26 \mathrm{mmol} \mathrm{g}^{-1}$. 

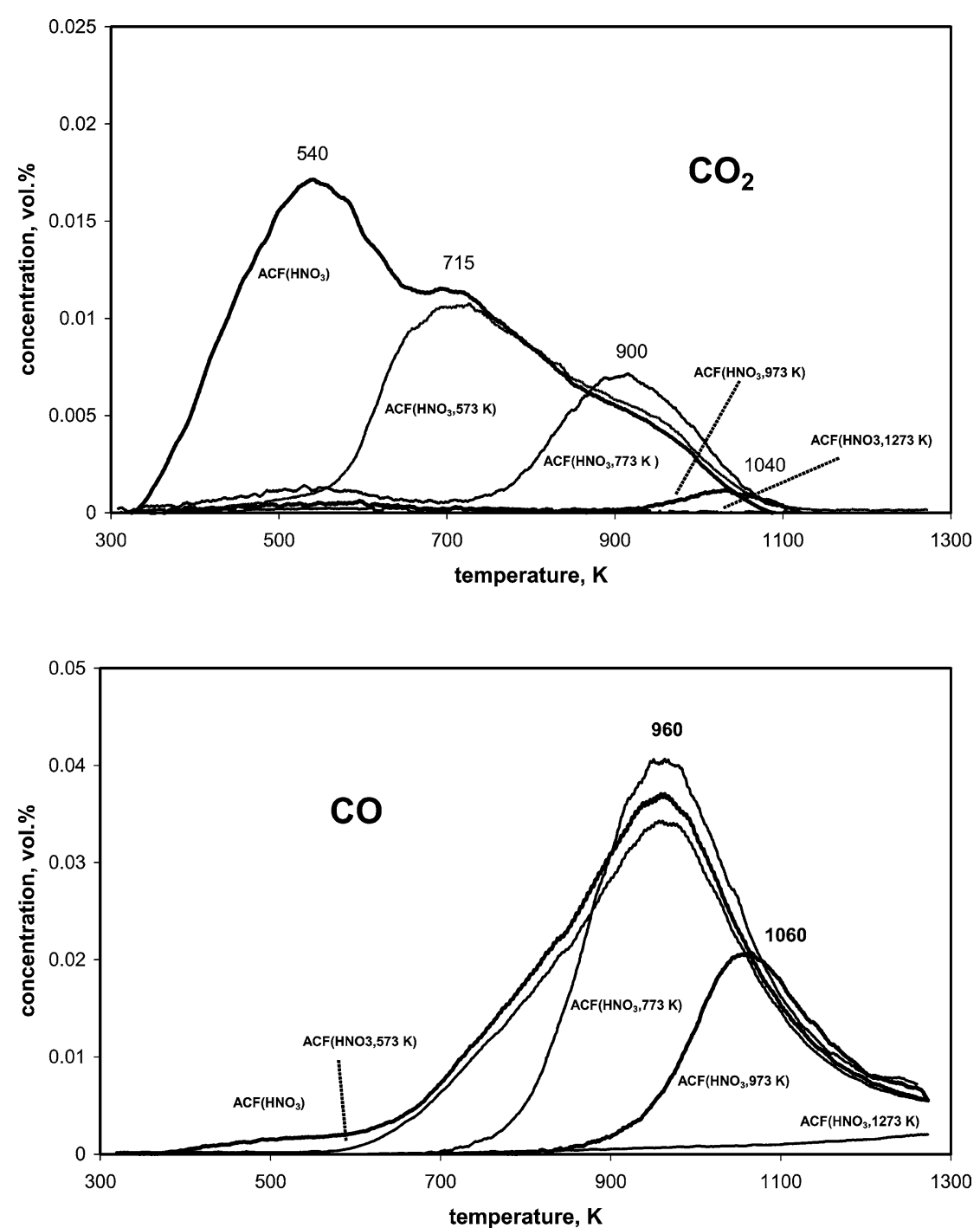

Fig. 3. TPD of the $\mathrm{ACF}\left(\mathrm{HNO}_{3}\right)$ supports $(0.01 \mathrm{~g})$ after their pretreatments in $\mathrm{He}$ at different temperatures.

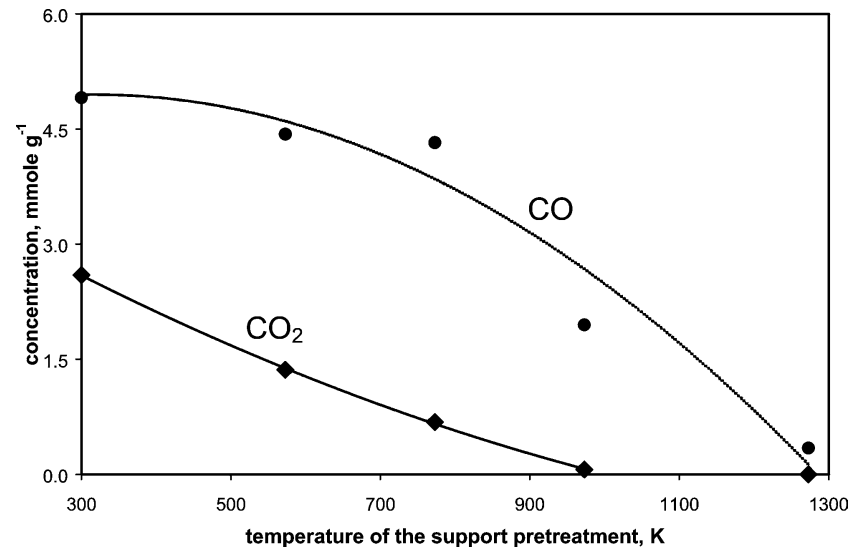

Fig. 4. Dependence of the amounts of $\mathrm{CO}$ and $\mathrm{CO}_{2}$ evolved during TPD from the $\mathrm{ACF}\left(\mathrm{HNO}_{3}\right)$ on the pretreatment temperature of the support in $\mathrm{He}$ for $30 \mathrm{~min}$.

At contrast, the support pretreated in $\mathrm{HNO}_{3}$ had a much higher concentration of the $\mathrm{CO}_{2}$ precursors $\left(2.6 \mathrm{mmolg}^{-1}\right.$, Fig. 4). Therefore, we suppose that a much higher amount

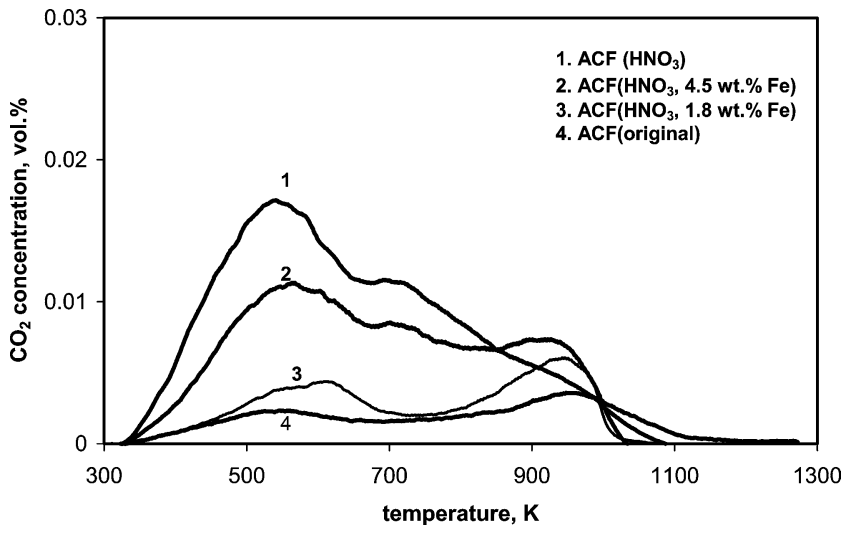

Fig. 5. $\mathrm{CO}_{2}$ evolution during TPD of the ACF supports ( $\left.0.01 \mathrm{~g}\right)$ after different pretreatments: effect of $\mathrm{HNO}_{3}$ pretreatment and iron oxide deposition.

of carboxylic hydroxyls were involved in Au deposition, resulting in the $0.8 \mathrm{wt} \% \mathrm{Au} / \mathrm{ACF}\left(\mathrm{HNO}_{3}\right)$ catalyst, which demonstrated much lower catalytic activity than the $1.1 \mathrm{wt} \%$ $\mathrm{Au} / \mathrm{ACF}$ (original) (Fig. 1). 


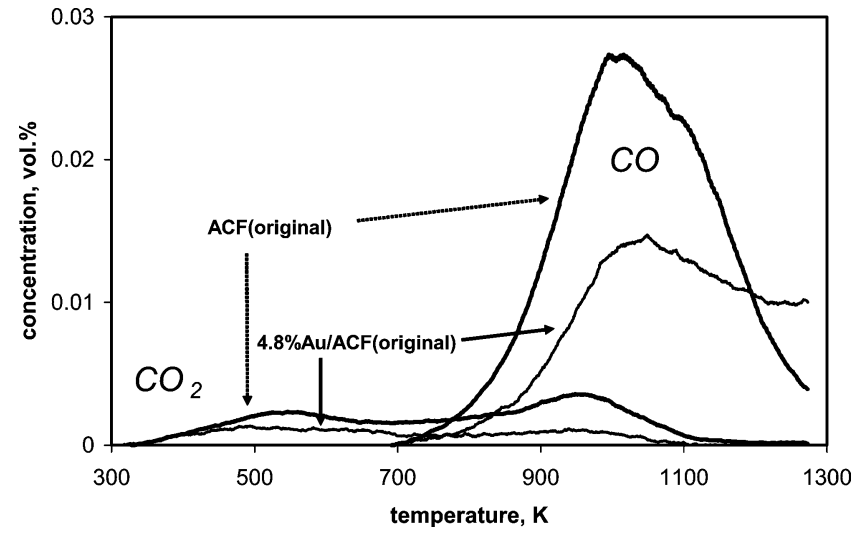

Fig. 6. $\mathrm{CO}$ and $\mathrm{CO}_{2}$ evolution during TPD: effect of $\mathrm{Au}(4.8 \mathrm{wt} \%)$ deposition on the $\mathrm{ACF}$ (original).

To understand what happens with $\mathrm{Au}$ after deposition and the reasons for low activity of the $0.8 \mathrm{wt} \% \mathrm{Au} / \mathrm{ACF}\left(\mathrm{HNO}_{3}\right)$, this sample was studied by HRTEM and XPS. The HRTEM image after deposition of $\left[\mathrm{Au}(\mathrm{en})_{2}\right] \mathrm{Cl}_{3}$ on $\mathrm{ACF}\left(\mathrm{HNO}_{3}\right)$, washing and drying in ambient air (before reduction in $\mathrm{H}_{2}$ ), is presented in Fig. 7. Metallic Au particles have a typical size of $2 \mathrm{~nm}$, while the maximum size does not exceed $5 \mathrm{~nm}$. The Au particles were distributed homogeneously within the porous structure of the carbon filament.

An XPS spectrum of the Au $4 f$ region ( $\mathrm{Au} 4 f_{7 / 2}$ and $\mathrm{Au}$ $\left.4 f_{5 / 2}\right)$ is also shown in Fig. 7. The spectrum was complex; therefore, it was deconvoluted into several components. The first doublet with peaks at 84.0 and $87.7 \mathrm{eV}$ is characteristic for metallic gold [31-34]. Metal $\mathrm{Au}^{0}$ represents $\sim 43 \%$ of the total gold deposited and was assigned to the particles of $2 \mathrm{~nm}$ observed by HRTEM (Fig. 7). Ionic gold species were difficult to detect by HRTEM, but were observed by XPS (Fig. 7).

The presence of chlorine was not found on the catalyst surface, indicating that washing procedure effectively removes $\mathrm{Cl}^{-}$ions. This excludes the possibility that any of the observed $\mathrm{Au}$ peaks correspond to chlorine-containing compounds [32]. The peaks of the second species (88.1 and $91.6 \mathrm{eV}$ ) are strongly shifted with respect to metallic gold and are assigned to $\mathrm{Au}^{3+}$-containing species representing $\sim 21 \%$ of the total $\mathrm{Au}$ amount. Similar peaks (87.7-88.2 and 91.4-91.8 eV) assigned to $\mathrm{Au}^{3+}$-hydroxy species $\left(\mathrm{Au}(\mathrm{OH})_{3}, \mathrm{Au}(\mathrm{OH})_{2}{ }^{+}\right)$were observed in nonreduced $\mathrm{Au} / \mathrm{Al}_{2} \mathrm{O}_{3}$ [31] and Au/Y-type zeolite [34] prepared by deposition/precipitation using $\mathrm{HAuCl}_{4}$.

$\mathrm{Au}_{2} \mathrm{O}_{3}$ cannot be responsible for these peaks since it presents signals at lower BE, 85.5-86.5 and 89.6 eV [31,34]. These species seems also to exist in the sample (not taken into account during the deconvolution), but with a much lower surface concentration than other species.

The third Au species provide the peaks at 84.9 and $88.6 \mathrm{eV}$ and gives $\sim 36 \%$ of the total Au present. The assignment of these peaks to certain gold species is confusing in the literature. While going from bulk gold to gold clusters with the size lower than $2 \mathrm{~nm}$, gold was claimed to loose its
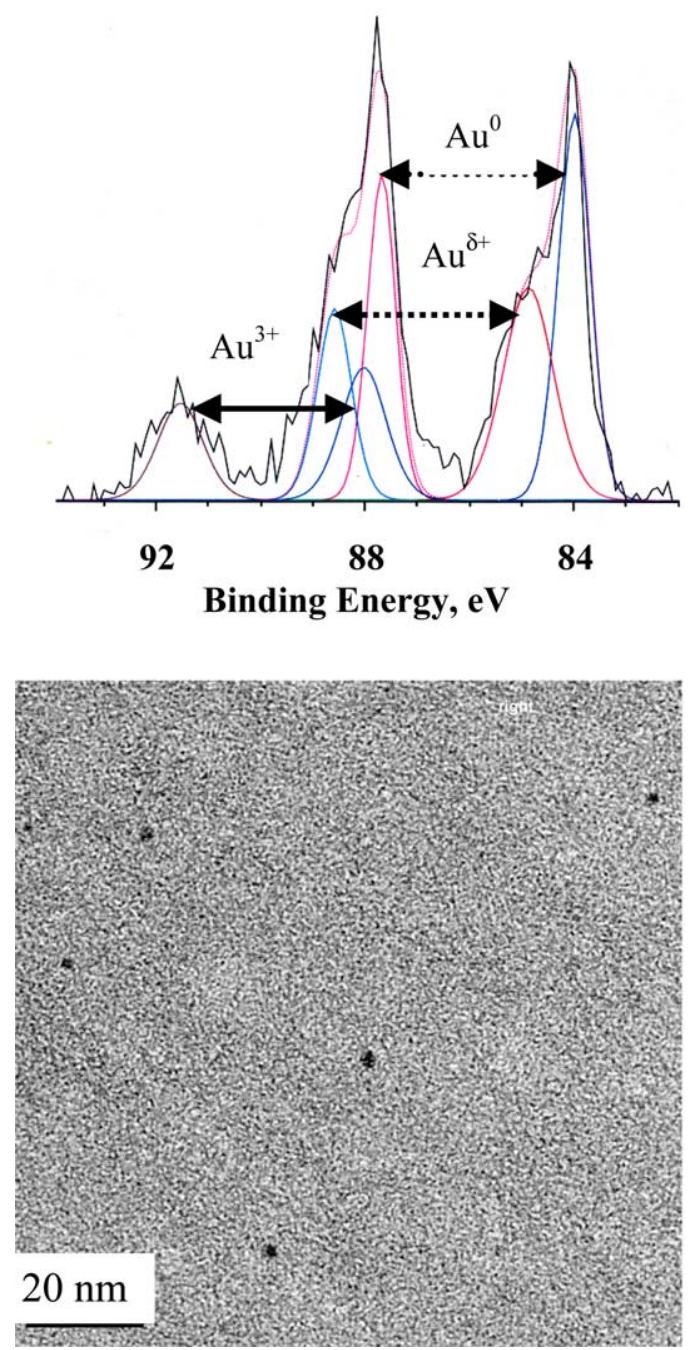

Fig. 7. XPS of the Au $4 f$ region and HRTEM image (elementary filament cut) of the $0.8 \% \mathrm{Au} / \mathrm{ACF}\left(\mathrm{HNO}_{3}\right)$ catalyst before reduction.

metallic properties, providing the shift in the $\mathrm{Au} 4 f$ peaks position toward higher BE [4,35]. However, for the studied sample containing Au supported on activated carbon, the metallic particles of $2 \mathrm{~nm}$ are supposed to be responsible for the peak of metallic gold at 84.0 and $87.7 \mathrm{eV}$ (Fig. 7). Hence, the peaks at 84.9 and $88.6 \mathrm{eV}$ were assigned to ionic gold species $\mathrm{Au}^{\delta+}$ in line with the reported data $\left(\mathrm{Au}^{3+}[32]\right.$ and $\left.\mathrm{Au}^{1+}[33]\right)$.

Thus, a study of the sample before the reduction in $\mathrm{H}_{2}$ finds gold species with different oxidation states. Besides $\mathrm{Au}^{3+}$, the reduced forms of gold, including small metallic particles of $2 \mathrm{~nm}$, are formed. Reductive properties of activated carbon are well-known $[9,16]$.

The $0.8 \mathrm{wt} \% \mathrm{Au} / \mathrm{ACF}\left(\mathrm{HNO}_{3}\right)$ sample was also characterized after reduction in $\mathrm{H}_{2}$ at $573 \mathrm{~K}$ by XPS and HRTEM. It is seen in Fig. 8 that the contribution of metallic gold ( 84.0 and $87.7 \mathrm{eV}$ ) gradually increases from 43 to $84 \%$. The species assigned to $\mathrm{Au}^{3+}(88.1$ and $91.6 \mathrm{eV})$ disappear completely. The $\mathrm{Au}^{\delta+}$ species $(84.9$ and $88.6 \mathrm{eV}$ ) are still present but their concentration decreases from 36 to $16 \%$. The com- 

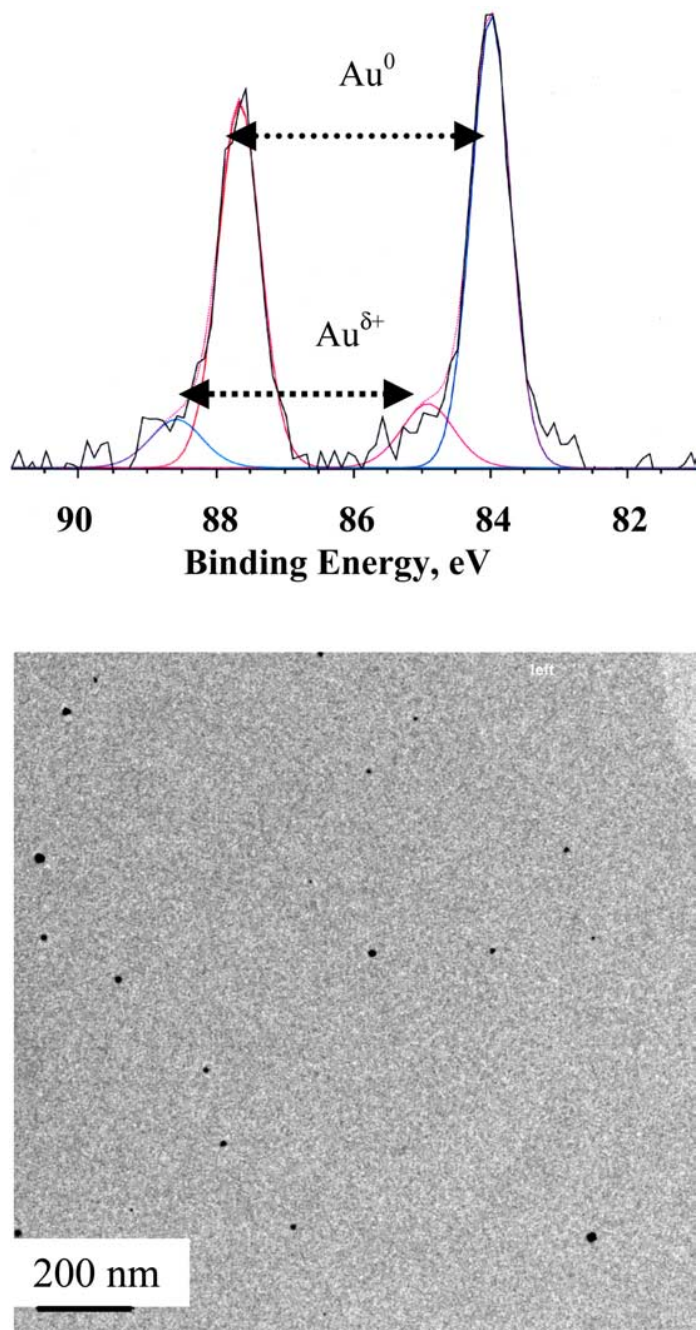

Fig. 8. XPS of the Au $4 f$ region and HRTEM image (elementary filament cut) of the $0.8 \% \mathrm{Au} / \mathrm{ACF}\left(\mathrm{HNO}_{3}\right)$ catalyst after reduction in $\mathrm{H}_{2}$ at $573 \mathrm{~K}$ for $30 \mathrm{~min}$.

plete reduction of gold species, which goes simultaneously with $\left[\mathrm{Au}(\mathrm{en})_{2}\right]$-complex decomposition on the carbon surface, demands severe conditions with temperatures up to $773 \mathrm{~K}$ in $\mathrm{H}_{2}$ (Fig. 2).

The HRTEM image of the sample after the reduction shows that the typical Au particle size increases up to $\sim 9 \mathrm{~nm}$ (Fig. 8). Particles of $\sim 20 \mathrm{~nm}$ were also observed. The latter particles are known to have negligible activity in $\mathrm{CO}$ oxidation [5]. The optimal Au size for $\mathrm{CO}$ oxidation was reported to be $\sim 3 \mathrm{~nm}[5,36]$. Hence, better Au-particles size distribution could be expected for the catalysts with the best activity like $0.7 \% \mathrm{Au} / \mathrm{ACF}\left(\mathrm{HNO}_{3}, 973 \mathrm{~K}\right)$ (Fig. 1). This sample was characterized by HRTEM after reduction in $\mathrm{H}_{2}$ at $573 \mathrm{~K}$ (Fig. 9). The typical Au particle size was in the range of $2.5-5 \mathrm{~nm}$ and remained the same after the $\mathrm{CO}$ oxidation at room temperature. However, some bigger $\mathrm{Au}$ particles up to $13 \mathrm{~nm}$ were also observed (not shown).

Thus, oxygen-containing functional groups on the ACF surface are involved in gold deposition. Their removal by thermal treatment at $1273 \mathrm{~K}$ results in the support not re-

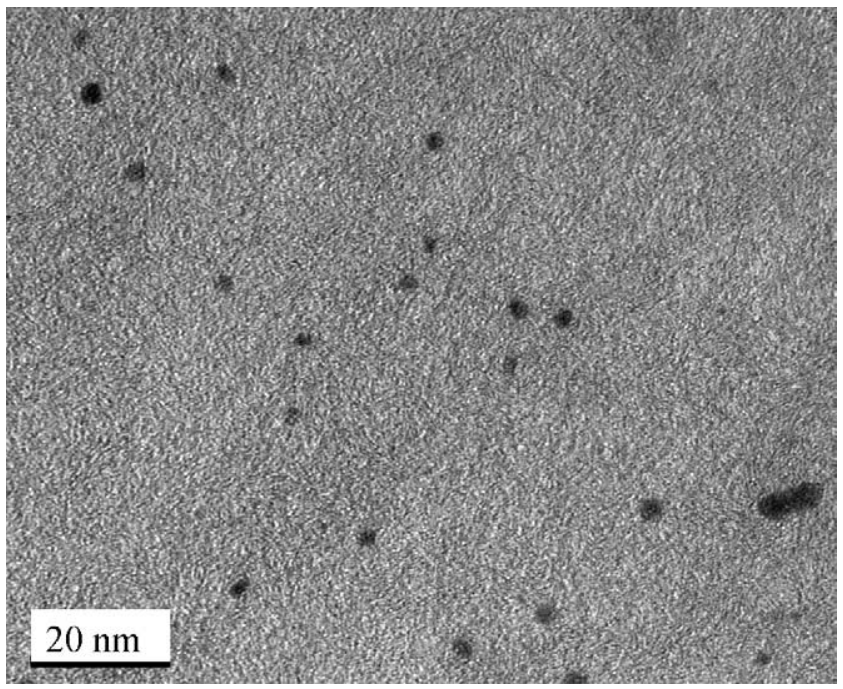

Fig. 9. HRTEM image (elementary filament cut) of the $0.7 \%$ $\mathrm{Au} / \mathrm{ACF}\left(\mathrm{HNO}_{3}, 973 \mathrm{~K}\right)$ catalyst after reduction in $\mathrm{H}_{2}$ at $573 \mathrm{~K}$ for $30 \mathrm{~min}$.

acting with $\left[\mathrm{Au}(\mathrm{en})_{2}\right] \mathrm{Cl}_{3}$ (Table 1). The mechanism of gold deposition on $\mathrm{AC}$ involves ion exchange of $\left[\mathrm{Au}(\mathrm{en})_{2}\right]^{3+}$ with the protons of the acidic groups on ACF, carboxylic and phenolic, which are known also to possess redox properties [7,37].

Phenolic groups are less acidic and chemically more stable than the carboxylic ones. Therefore, carboxylic groups were selectively removed from the ACF surface by thermal pretreatment in $\mathrm{He}$ at $973 \mathrm{~K}$ (Figs. 3 and 4), while phenolic groups were left on the surface. They interacted with $\left[\mathrm{Au}(\mathrm{en})_{2}\right] \mathrm{Cl}_{3}$ precursor by anchoring the gold cations:

(--OH $+\mathrm{Au}^{3+} \rightarrow$ (--O- $\mathrm{Ou}^{3+}+\mathrm{H}^{+}$.

The reduction of such cations by hydrogen at temperatures of 573-773 K led to the formation of metallic nanoparticles $(<5 \mathrm{~nm}$, Fig. 9) possessing high catalytic activity during $\mathrm{CO}$ oxidation (Fig. 2, Table 2).

Interaction of $\left[\mathrm{Au}(\mathrm{en})_{2}\right] \mathrm{Cl}_{3}$ solution with less stable ACF surface carboxylic groups results in surface decarboxylation and reduction of $\mathrm{Au}(\mathrm{III})$ to $\mathrm{Au}(0)$ :

(C)- $\mathrm{COOH}+\mathrm{Au}^{3+} \rightarrow$ ( $)+\mathrm{Au}^{0}+\mathrm{H}^{+}+\mathrm{CO}_{2} \uparrow$.

The considerable decrease in the content of carboxylic groups on the ACF was observed after Au deposition (Fig. 6). At the same time, small metallic Au particles $(\sim 2 \mathrm{~nm})$ were seen by HRTEM and XPS (Fig. 7). During reductive activation in $\mathrm{H}_{2}$ at $573 \mathrm{~K}$, such particles serve as nucleation centers for the formation of bigger agglomerates $(>9 \mathrm{~nm}$ ) (Fig. 8), which are supposed to be inactive during $\mathrm{CO}$ oxidation. These undesirable big agglomerates can be formed due to two processes. The first is assumed to start from the reduction in hydrogen of Au cations, forming metal clusters, which migrate along the surface until collision with similar clusters, resulting in coalescence. The second process may involve Ostwald ripening when primary 
Table 2

Catalytic activity of gold catalysts $(0.006-0.02 \mathrm{~g})$ in $\mathrm{CO}$ oxidation at room temperature $\left(1 \mathrm{vol} \% \mathrm{CO}, \mathrm{O}_{2} / \mathrm{CO}=5,100 \mathrm{ml}(\mathrm{STP}) / \mathrm{min}\right)$

\begin{tabular}{|c|c|c|}
\hline Catalyst & $\begin{array}{l}\text { Activity after } 0.5 \mathrm{~h} \\
\left(\mathrm{mmol}_{\mathrm{CO}} \mathrm{g}_{\mathrm{Au}}^{-1} \mathrm{~s}^{-1}\right)\end{array}$ & $\begin{array}{l}\text { Activity after } 2 \mathrm{~h} \\
\left(\mathrm{mmol}_{\mathrm{CO}} \mathrm{g}_{\mathrm{Au}}^{-1} \mathrm{~s}^{-1}\right)\end{array}$ \\
\hline $1.1 \% \mathrm{Au} / \mathrm{ACF}$ (original), reduced at $773 \mathrm{~K}$ & 0.17 & 0.074 \\
\hline $0.7 \% \mathrm{Au} / \mathrm{ACF}\left(\mathrm{HNO}_{3}, 973 \mathrm{~K}\right)$, reduced at $773 \mathrm{~K}$ & 0.21 & 0.10 \\
\hline $1.3 \% \mathrm{Au} / \mathrm{FeO}_{x} / \mathrm{ACF}\left(\mathrm{HNO}_{3}, 4.5 \mathrm{wt} \% \mathrm{Fe}\right)$, reduced at $573 \mathrm{~K}$ & 0.26 & 0.12 \\
\hline $0.5 \% \mathrm{Au} / \mathrm{FeO}_{x} / \mathrm{ACF}\left(\mathrm{HNO}_{3}, 1.8 \mathrm{wt} \% \mathrm{Fe}\right)$, reduced at $573 \mathrm{~K}$ & 0.8 & 0.36 \\
\hline
\end{tabular}

$\mathrm{Au}$ particles formed during ion exchange grow at the expense of small clusters [38] formed during reduction in $\mathrm{H}_{2}$. But regardless of the cause, formation of big agglomerates leads to a decline in catalytic activity and should be avoided.

\section{4. $\mathrm{CO}$ oxidation over $\mathrm{Au} / \mathrm{Fe} \mathrm{O}_{x} / \mathrm{ACF}$ catalysts and their characterization}

The data presented in Table 2 show that the activity of the Au catalysts could be also improved by modification of the $\mathrm{ACF}\left(\mathrm{HNO}_{3}\right)$ by iron oxide. The activity of $\mathrm{FeO}_{x} / \mathrm{ACF}$ was found to be 40-500 times lower as compared to $\mathrm{Au} / \mathrm{FeO}_{x} / \mathrm{ACF}$ catalyst, indicating that supported iron oxide itself is not active in $\mathrm{CO}$ oxidation at room temperature.

The TPD profile of the $\mathrm{FeO}_{x} / \mathrm{ACF}\left(\mathrm{HNO}_{3}\right)$ differs considerably from the TPD profile of $\mathrm{ACF}\left(\mathrm{HNO}_{3}\right)$ (Fig. 5). The deposition of iron oxide on $\mathrm{ACF}\left(\mathrm{HNO}_{3}\right)$ results in a decrease in $\mathrm{CO}_{2}$ evolution during TPD, but not $\mathrm{CO}$ evolution, indicating the destruction mostly of carboxylic groups. Hence, it could be expected that the Au particles have smaller size on the ACF modified by iron oxide and are more uniform. In accordance, the HRTEM/EDAS study of the $1.3 \%$ $\mathrm{Au} / \mathrm{FeO}_{x} / \mathrm{ACF}$ (Fig. 10) evidently shows the presence of relatively uniform $\mathrm{Au}$ nanoparticles with a typical size of $\sim 5 \mathrm{~nm}$. These particles are located inside the porous carbon filament. Iron was found in the form of $\mathrm{Fe}_{2} \mathrm{O}_{3}$ [10]. Contrary to $\mathrm{Au}, \mathrm{Fe}_{2} \mathrm{O}_{3}$ particles in this sample are located only on the external surface of the elementary filament and there was no interaction observed between gold and $\mathrm{Fe}_{2} \mathrm{O}_{3}$ (Fig. 10). This conclusion was also confirmed by a study of the catalysts after the CO oxidation by 3D microscopy and HRTEM/EDAS methods [10]. Hence, the enhanced catalytic activity of the $\mathrm{Au} / \mathrm{FeO}_{x} / \mathrm{ACF}$ catalysts is assigned to smaller and more uniform $\mathrm{Au}^{0}$ particles due to selective removal of carboxylic surface groups by iron oxide predeposition on $\mathrm{ACF}\left(\mathrm{HNO}_{3}\right)$. The effect of iron oxide predeposition is similar to the effect of the thermal pretreatment of the $\mathrm{ACF}\left(\mathrm{HNO}_{3}\right)$ support.

\section{Conclusions}

1. Metallic gold nanoparticles with an optimal size of 2$5 \mathrm{~nm}$ supported on activated carbon (in the form of granules or structured woven fabrics) are highly active during $\mathrm{CO}$ oxidation at room temperature. Heating of the $\mathrm{Au}$ catalysts in $\mathrm{H}_{2}$ at $773 \mathrm{~K}$ before the reaction is necessary to obtain high activity.

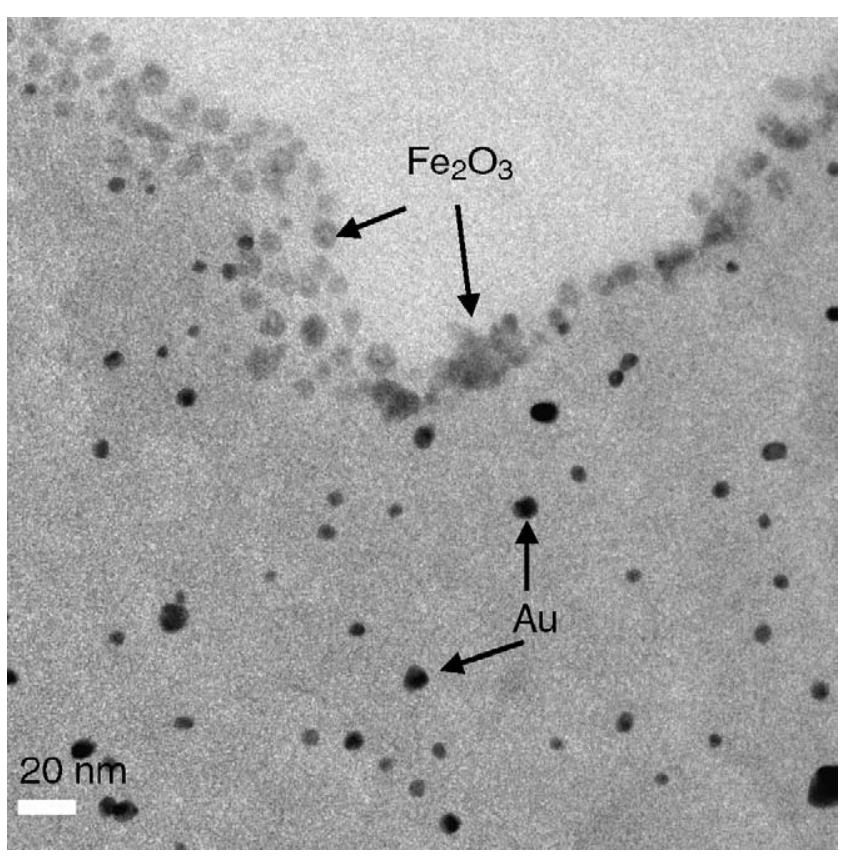

Fig. 10. HRTEM image (elementary filament cut) of the $1.3 \%$ $\mathrm{Au} / \mathrm{FeO} \mathrm{O}_{x} / \mathrm{ACF}\left(\mathrm{HNO}_{3}, 4.5 \mathrm{wt} \% \mathrm{Fe}\right)$ catalyst after reduction in $\mathrm{H}_{2}$ at $573 \mathrm{~K}$ followed by $\mathrm{CO}$ oxidation at room temperature.

2. To form highly dispersed Au nanoparticles, gold was deposited on activated carbon fibers (ACF) from $\left[\mathrm{Au}(\mathrm{en})_{2}\right] \mathrm{Cl}_{3}$ solution via ion exchange with the protons of carboxylic and phenolic surface groups.

3. Surface phenolic groups were able to chemically anchor gold in cationic form, leading after reduction in $\mathrm{H}_{2}$ to small $\mathrm{Au}^{0}$ nanoparticles $(<5 \mathrm{~nm})$ on ACF.

4. Surface carboxylic groups were observed to decompose during interaction with $\left[\mathrm{Au}(\mathrm{en})_{2}\right] \mathrm{Cl}_{3}$ solution forming metallic Au clusters $(\sim 2 \mathrm{~nm})$. Upon reductive activation in $\mathrm{H}_{2}$ at $573 \mathrm{~K}$ such clusters serve as nucleation centers for the formation of big agglomerates $(>9 \mathrm{~nm})$, which are inactive during $\mathrm{CO}$ oxidation.

5. To control the Au-nanoparticle sizes, the ACF pretreatment was designed to attain chemical uniformity of the surface groups. This pretreatment involves carbon surface oxidation by $\mathrm{HNO}_{3}$ followed by either calcination in $\mathrm{He}$ (773-973 K) or by iron oxide deposition. The resulting ACF surface contains mainly phenolic groups. 


\section{Acknowledgments}

The authors acknowledge the Swiss National Science Foundation and the Swiss Commission of Technology and Innovation (CTI, Bern) for financial support in the framework of TOPNANO 21 program. The authors thank Prof. A. Renken for fruitful discussions. The work of Ms. A. Udriot for the chemical analysis, Mr. E. Casali for the SSA measurements, and Mr. N. Xanthopoulos for the XPS analysis is highly appreciated.

\section{References}

[1] M. Haruta, Cattech 6 (2002) 102.

[2] M. Haruta, M. Date, Appl. Catal. A 222 (2001) 427.

[3] G.C. Bond, D.T. Thompson, Gold Bull. 33 (2000) 41.

[4] T.V. Choudhary, D.W. Goodman, Top. Catal. 21 (2002) 25.

[5] M. Haruta, Catal. Today 36 (1997) 153.

[6] S.D. Lin, M. Bollinger, M.A. Vannice, Catal. Lett. 17 (1993) 245.

[7] E. Auer, A. Freund, J. Pietsch, T. Tacke, Appl. Catal. A 173 (1998) 259.

[8] C. Bianchi, F. Porta, L. Prati, M. Rossi, Top. Catal. 13 (2000) 231.

[9] L. Prati, G. Martra, Gold Bull. 32 (1999) 96.

[10] D.A. Bulushev, L. Kiwi-Minsker, I. Yuranov, E.I. Suvorova, P.A. Buffat, A. Renken, J. Catal. 210 (2002) 149.

[11] S.R. de Miguel, J.I. Villella, E.L. Jablonski, O.A. Scelza, C.S.M. de Lecea, A. Linares-Solano, Appl. Catal. A 232 (2002) 237.

[12] E. Joannet, C. Horny, L. Kiwi-Minsker, A. Renken, Chem. Eng. Sci. 57 (2002) 3453.

[13] Y.F. Jia, K.M. Thomas, Langmuir 16 (2000) 1114.

[14] R.W. Fu, H.M. Zeng, Y. Lu, Mineral. Eng. 6 (1993) 721.

[15] M. Uchida, O. Shinohara, S. Ito, N. Kawasaki, T. Nakamura, S. Tanada, J. Colloid Interface Sci. 224 (2000) 347.

[16] P.A. Simonov, A.V. Romanenko, I.P. Prosvirin, G.N. Kryukova, A.L. Chuvilin, S.V. Bogdanov, E.M. Moroz, V.A. Likholobov, Stud. Surf. Sci. Catal. 118 (1998) 15.
[17] P.A. Simonov, A.V. Romanenko, I.P. Prosvirin, E.M. Moroz, A.I. Boronin, A.L. Chuvilin, V.A. Likholobov, Carbon 35 (1997) 73.

[18] P. Riello, P. Canton, A. Benedetti, Langmuir 14 (1998) 6617.

[19] H.P. Boehm, Carbon 40 (2002) 145.

[20] S. Haydar, C. Moreno-Castilla, M.A. Ferro-Garcia, F. Carrasco-Marin, J. Rivera-Utrilla, A. Perrard, J.P. Joly, Carbon 38 (2000) 1297.

[21] J.L. Figueiredo, M.F.R. Pereira, M.M.A. Freitas, J.J.M. Orfao, Carbon 37 (1999) 1379.

[22] G. delaPuente, J.J. Pis, J.A. Menendez, P. Grange, J. Anal. Appl. Pyrol. 43 (1997) 125.

[23] F. Xie, J. Phillips, I.F. Silva, M.C. Palma, J.A. Menendez, Carbon 38 (2000) 691.

[24] M.A. Fraga, E. Jordao, M.J. Mendes, M.M.A. Freitas, J.L. Faria, J.L. Figueiredo, J. Catal. 209 (2002) 355.

[25] A.E. Aksoylu, M. Madalena, A. Freitas, M.F.R. Pereira, J.L. Figueiredo, Carbon 39 (2001) 175.

[26] A. Sepulveda-Escribano, F. Coloma, F. Rodriguez-Reinoso, Appl. Catal. 173 (1998) 247.

[27] C.L. Bianchi, S. Biella, A. Gervasini, L. Prati, M. Rossi, Catal. Lett. 85 (2003) 91.

[28] B.P. Block, J.C. Bailar, J. Am. Chem. Soc. 73 (1951) 4722.

[29] R.J.H. Grisel, B.E. Neiuwenhuys, Catal. Today 64 (2001) 69.

[30] U. Zielke, K.J. Huttinger, W.P. Hoffman, Carbon 34 (1996) 983.

[31] E.D. Park, J.S. Lee, J. Catal. 186 (1999) 1.

[32] A.M. Visco, F. Neri, G. Neri, A. Donato, C. Milone, S. Galvagno, Phys. Chem. Chem. Phys. 1 (1999) 2869.

[33] S. Minico, S. Scire, C. Crisafulli, S. Galvagno, Appl. Catal. B 34 (2001) 277.

[34] J.N. Lin, J.H. Chen, C.Y. Hsiao, Y.M. Kang, B.Z. Wan, Appl. Catal. B 36 (2002) 19.

[35] C.N.R. Rao, V. Vijayakrishnan, H.N. Aiyer, G.U. Kulkarni, G.N. Subbanna, J. Phys. Chem. 97 (1993) 11157.

[36] C.C. Chusuei, X. Lai, K. Luo, D.W. Goodman, Top. Catal. 14 (2001) 71.

[37] D.S. Cameron, S.J. Cooper, I.L. Dodgson, B. Harrison, J.W. Jenkins, Catal. Today 7 (1990) 113.

[38] D.C. Meier, L. Xiaofeng, D.W. Goodman, in: A.F. Carley, et al. (Eds.), Surface Chemistry and Catalysis, Kluwer Academic/Plenum Publishers, New York, 2002, p. 147. 